\title{
Community-Based Participatory Research in Practice-Based Research Networks
}

\author{
Jobn M. Westfall, MD, MPH \\ Rebecca F. VanVorst, MSPH ${ }^{1}$ \\ Deborab S. Main, PbD ${ }^{1}$ \\ Carol Herbert, $M D^{2}$ \\ ${ }^{1}$ University of Colorado Health Sciences \\ Center, UCHSC at Fitzsimons, Aurora, Colo \\ ${ }^{2}$ Schulich School of Medicine \& Dentistry, \\ University of Western Ontario, London, \\ Ontario, Canada
}

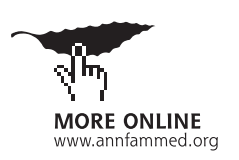

\begin{abstract}
PURPOSE We wanted to describe community-based participatory research in practice-based research networks in the United States.

METHODS We surveyed all identified practice-based research networks (PBRNs) in the United States to find out whether they had a mechanism for obtaining feedback or involvement from the community of patients served by PBRN physicians. We asked open-ended questions on how they involve community members and whether they had plans for future involvement of community members and/or patients.
\end{abstract}

RESULTS We received 46 completed questionnaires (71\% response rate). Twentyfour reported that they have some mechanism to involve community members and/ or patients in their research. No PBRN reported full participatory methods; however, several PBRNs reported active involvement by community members to generate research ideas, review research protocols, interpret results, and disseminate findings.

CONCLUSION While perhaps not meeting the classical definition of CBPR, some PBRNs are involving community members and patients in their research. There is a wide spectrum of involvement by community members in PBRN research. Many PBRNs reported plans to involve community members in their research. We believe that community involvement will enhance PBRN research.

Ann Fam Med 2006;4:8-14. DOI: 10.1370/afm.511

\section{INTRODUCTION}

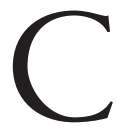
ommunity-based participatory research (CBPR) is an emerging model of research aimed at enhancing the relevance and value of clinical research by involving patients and community members. ${ }^{1}$ Growing out of grassroots community organizing, CBPR has emerged as an important method in primary care and epidemiologic research. ${ }^{2} \mathrm{CBPR}$ is a "systematic investigation, with the collaboration of those affected by the issue being studied."3 One goal of CBPR is to ground clinical research in real-life patient experience. CBPR is a participatory, cooperative, and colearning process for researchers and community members.

The growing popularity and effective use of this approach is supported in the literature. Community-based participatory research has been conducted on nearly all aspects of health care, including ambulatory mental health care, ${ }^{4}$ rural care of patients with human immunodeficiency virus infection, ${ }^{5}$ community adolescent diabetes prevention, hospitalized malnourished children, ${ }^{6}$ and health promotion in immigrant women. ${ }^{7}$ Several agencies and organizations important to primary care are also recognizing the importance of this research approach. A document entitled "Responsible Research with Communities: Participatory Research in Primary Care" was adopted as organizational policy by the North American Primary Care Research Group Board of Directors at its annual meeting in $1998 .{ }^{8,9}$

Practice-based research networks (PBRNs) have been doing participatory research for decades by actively involving practicing primary care physicians in generating research ideas and conducting research in their 
practice settings. ${ }^{10,11}$ This participatory research model, however, does not usually involve another key stakeholder in primary care practice-based research-the patient or community member.

Community participation in PBRN research is a new frontier, and few PBRNs actively engage the community in their research. With the growing support for community involvement, research conducted within PBRNs needs to expand its reach beyond practicing clinicians to community members. The Agency for Healthcare Research and Quality (AHRQ) included requirements for PBRN-related requests for applications (RFAs) to develop and describe ways of obtaining patient input from communities in which PBRNs serve. ${ }^{12}$ The Centers for Disease Control and Prevention and the National Institutes of Health (NIH) have both released RFAs to support community-based participatory research. ${ }^{13,14}$ This expanded funding pool for CBPR may be an incentive for PBRNs to consider involving community members in their research.

The purpose of this article is to describe the use of community-based participatory research methods among PBRNs in the United States.

\section{METHODS}

We developed a survey instrument to learn whether and how PBRNs are incorporating community-based participatory research in their network. Because we found no literature on CBPR in PBRNs, our study was aimed at exploring all the ways PBRNS involved community members in research. We chose the AHRQ description of community involvement because it is nonspecific and provided a baseline from which respondents could expand: a PBRN should "document in their proposals that ... a mechanism (such as a community advisory board) is in place to solicit advice/feedback from the communities of patients served by the PBRN clinicians." Immediately after this description, we asked PBRNs to indicate whether and how they met this description. We asked participants how this was working and about any future plans for developing or changing this mechanism within their PBRN.

We distributed the questionnaire to all US PBRNs listed as full members in the Federation of Practice Based Research Networks, the AHRQ Resource Center list of PBRN grantees, and searched the Internet and medical literature for other PBRNs. We found that many networks were not truly practice-based research networks but had the term network in their name (eg, Family Practice Inquiries Network). Several of the PBRNs were no longer in existence, had joined another PBRN, or had simply closed. Our final sample included 65 PBRNS in the United States.
A cover letter describing the survey instrument and requesting information on the PBRNs' use of participatory research was mailed to the identified director of each PBRN. We asked the director or the coordinator to complete the 5-minute questionnaire. We requested those PBRNs that had recently written an AHRQ grant proposal to send the paragraph from the grant where they describe how they meet the criteria for community involvement and feedback. We sent a second questionnaire to nonrespondents 2 to 4 weeks after the initial mailing. This study was approved by the Colorado Multiple Institutional Review Board.

The answers to open-ended questions served as our primary data for analysis. All responses were entered into Microsoft Word documents. The authors participated in analysis using an editing approach to analysis, a technique derived from grounded theory. ${ }^{15}$ This approach encourages interpretation of the data using a team approach. Authors read through the responses, highlighted particular issues and themes, and identified representative quotes. The team communicated by email and telephone conversations to review these findings, group similar issues, and expand on themes. These themes were then organized and described within the Results and Discussion.

We classified community involvement in a hierarchical manner from no involvement to full participation in research idea generation and conduct of research. For respondents who reported multiple types of activities, we placed them in the highest reported category.

\section{RESULTS}

We received 46 completed questionnaires - a $71 \%$ response rate. Forty-one respondents represented primary care networks, of which 19 were predominantly family medicine, 5 were pediatric, 3 were internal medicine, and 14 were multidisciplinary or unknown. Three were nursing networks and 2 were networks that were a combination of medical, nursing, public health, and payor institutions. Of the responding PBRNs, 20 reported that they did not meet the description of community involvement provided by AHRQ, 26 reported that they $\mathrm{did}_{i} 2$ respondents reporting that they met these criteria had included only PBRN physicians, not community members, in their research. Table 1 describes the type of community involvement reported by respondents.

Types of Participation by Community Members Many of the PBRNs reported that they had advisory boards or committees composed of key stakeholders, such as physicians, insurers, and public health care groups. These PBRNs described several models of advi- 


\begin{tabular}{|lc|}
\hline $\begin{array}{l}\text { Table 1. Types of Community Participation in Research } \\
\text { Reported by Practice-Based Research Neworks (N = 46) }\end{array}$ \\
\hline $\begin{array}{c}\text { PBRNs Reporting } \\
\text { This Activity } \\
\text { N (\%) }\end{array}$ \\
Type of Community Involvement & $22(48)$ \\
\hline No community involvement & $1(2)$ \\
Input through patient surveys & $1(2)$ \\
Study-specific focus groups & $11(24)$ \\
Community membership in existing PBRN board or council & $3(7)$ \\
Provides review and feedback only & $1(2)$ \\
Participates in generating research ideas, analyzing data & $2(4)$ \\
Conducts their own research project & $5(11)$ \\
Community involvement reported but activities unknown & $13(28)$ \\
Plans for increasing community member involvement & \\
\hline PBRN = practice-based research network. & \\
\hline
\end{tabular}

sory groups that informed their research efforts. Some PBRNs used existing advisory groups from the participating practices. Federally Qualified Health Centers are required to have an advisory board composed of patients, and several PBRNS reported using this existing model:

"We have community advisory boards for each community health center served by the - which owns and runs all 17 sites in our PBRN."

"We have a board of directors made up of family doctors, representatives from insurance companies, patient advocacy groups, university members, and quality improvement organizations. This board offers general advisement. For each specific research project, we include representative participants from the groups studied in a feedback and advisory capacity."

"For different projects from time to time we have had patient focus groups to guide our interventions."

"We have a patient with no medical connections on our board of directors."

Several PBRNS described community advisory boards composed mostly of patients and/or community members, not clinicians or other health related professionals. Some reported that their community member role was used primarily to offer suggestions for new research and review current research proposals:

"We have a parent advisory board recruited from among our practices. They meet to discuss our research agenda and provide feedback on our plans."

"We have a community advisory board that meets quarterly to be briefed on current projects, gather community input and solicit ideas for new studies."

We found 2 PBRNs had an active community group that performed many of the roles noted above, and they were more actively involved in research generation and implementation:

"The CAB reviews all network studies for value of the research question, appropriateness of methods and responsiveness to community standards, safety of participants and researchers, and fairness. Additionally, the CAB is working on developing their own study for the PBRN to conduct. Network staff will assist in developing methods for the study and the CAB will modify and approve them."

"Our community advisory council is composed of farmers, ranchers, school teachers, retired administrators. They review all our research, help us refine the methods, help get rid of our academic researchy language, and help interpret our results. They are working on identifying their own research project on methamphetamine abuse. Their input has lead to substantial changes in research design."

No respondent reported using participatory research methods as described by Macaulay et al in the NAPCRG policy statement. ${ }^{9}$

\section{How Well Is It Working?}

Respondents reported their own perceptions of how successfully they involved community members in their practice-based research. Some respondents believed that their groups were working well. Most respondents, however, reported that their community advisory groups were very new, and it was too early to evaluate their impact on research:

"Too early to tell."

"... we have only met once. This is an area that we need to improve."

"Yes, it is working well."

"Thus far is seems helpful and we are benefiting from his good advice."

"Our Community Advisory Council has far exceeded our expectations. They started out very confused on why we wanted their input. Over the year that we have met, they have become a cohesive group that has helped review studies, changed our methods for a rural survey, and interpreted our results. They have authored several newspaper articles on the network and research results. They are active in a study on colon cancer screening, really directing the language we use and the message we deliver."

\section{Future Plans}

When asked about future plans for involving patients or community members in their research, responses varied from having no plans for patient or community member involvement, plans for a minimal role, or plans for patients or community members to have a more active, ongoing role. Some did not explicitly indicate 
that their PBRNS would have a future role involving patients or community members:

"We have invited an expert on CBPR to make a presentation."

"We are first developing a physician advisory group A step after that would be to discuss a patient advisory group. Our difficulty is that our network is far-flung, with practices in many different cities over a several hundred mile area, and a patient group would be a token at best."

Some reported future plans of developing or engaging a community advisory group:

"We may involve patients of network clinicians on the advisory committees for specific projects."

"We are in the planning stages of developing a community board."

"We have written new grants that will use patient advisory committees as part of the development process."

"In the future, and as proposed in a recent $\mathrm{NIH}$ application on behalf of our network, we will hold an annual meeting of community representatives to solicit feedback."

".... [T] wo to 3 patients (who represent the community served at each network site) will be selected by the network physicians and practice site coordinators and informed of both the network's research plans and the development of research initiatives at the local site. Community members at all sites will serve in an advisory capacity to provide both advice and feedback about proposed research project and to give their input about projects that might be particularly relevant in the community that a specific network site serves."

"A community advisory group will be convened by the PBRN Coordinating Center shortly after the beginning of the study. The purpose of the 1-hour discussion will be to advise the network ... especially to meet the needs of the diverse populations within those communities."

Other PBRN respondents indicated that their plans include more frequent and active engagement of their community members:

"We are creating a 'virtual advisory board' of patients only, which will meet by conference call at least twice yearly. As we are a statewide network ... over 700 miles end to end, travel becomes a problem in getting volunteers together in person."

"Our future plans are to increase the membership of community persons from 2 to $3-5$ so that we can get more input from the community and to form our proposed local primary care coalitions in each community."

\section{Barriers}

Respondents listed and discussed many barriers to using a participatory research approach in their PBRN. Some respondents reported that participatory research was outside the scope of their network's current interest or ability, whereas others reported that it was unnecessary for their network's success. Most respondents reported concrete examples of problems they perceive or problems they have directly faced:

"We are so early in the network development that we have not yet felt strong enough to bring an advisory board into place."

"It is difficult to find times when they are free. Their feedback has been very valuable."

"It works great on paper and that is how it works best. The type of research we do is always listening to the doctors and patients that we are studying, and so the requirement is a bit superficial in one sense. If we were doing high-risk RCTs, I suspect the need would be greater."

"We have had lots of issues, most importantly regarding data sharing (even before HIPPA) and multiple IRBs."

"... the problem here is travel. [It] is a huge areaand timing-many of the residents work 2 to 3 jobs and simply do not have the time."

"Another is language-most are Spanish speaking - and intimidation and concerns about INS (anything official or involving professionals can stimulate this concern)."

"... challenging to design a community board to reflect the national representation."

"I also have grave concerns about bringing together a group of patients implying that their recommendations will have any impact on the operations of a clinic or research program when the hospital many not allow it. It feels like a sham."

\section{DISCUSSION}

This study is the first to describe the use of community-based participatory research methods by practice-based research networks. PBRNs have historically focused on involving the community of clinicians in their research. In the past few years PBRNs have begun looking for ways of involving the community of patients. We found that few PBRNs actively involve community members in research. Many are interested in this approach and are planning to do more. Most report considerable barriers to involving community members in their PBRN research.

It is evident that there is no commonly accepted application of community-based participatory research principles within practice-based research networks. In a 2003 survey of members of the North American Primary Care Research Group to determine penetration of the organizational policy document "PR in Primary 
Care" and current participatory research being done in primary care (unpublished, C. Herbert), respondents appeared to have different working definitions of participatory research, which made it difficult to interpret the results. Interpretations varied from the full engagement of community members in setting the research questions, in analyzing the data, and in interpreting the findings according to the definition of participatory action research to very limited involvement of community members or patients. This lack of a commonly accepted application of participatory research may be the case in the current survey as well. Guidelines have been developed, however, for assessing the degree of community participation at all stages of the research process, from development of the research question to analysis of the data and presentation of the results. A community guidebook has been published that can be used by community groups and organizations in planning, implementing, and evaluating participatory research projects. ${ }^{16}$ Use of these guidelines may provide assistance to PBRNs as they work to implement CBPR principals in their research.

Using the limited AHRQ description of CBPR, we found about one half of PBRNs involved community members or patients in at least some aspect of their research. For those that did involve community members, it was most often in an occasional or project-specific advisory role. Only a few PBRNs have community members more actively involved in research idea generation, review and input on methods, data analysis and interpretation, and dissemination of results. Two PBRNs reported conducting research generated by community member ideas.

Our findings on community participation are not unique to PBRNs. Many of the issues identified by our respondents are echoed in the literature on communitybased participatory research and participatory action research. Two major themes emerged: issues related to academic and financial support for community involvement, and issues related to identification and expectations of the community.

Difficulty in identification of "community" was illustrated by the following response, "... challenging to design a community board to reflect the national representation." The expansion of the community beyond the clinicians may be a difficult step both conceptually and practically. Because PBRNs grew from the notion of physician participation, there may be a perception that involving community members in research will dissuade physicians from participating. Many PBRNs cover large geographic regions with diverse populations; in such situations, involving community members may be impractical, costly in terms of time and money, and not representative of the PBRN as a whole.
Several respondents reported that it seemed inappropriate to ask community members to participate when it was unlikely that their ideas would be acted upon. Ammerman et $\mathrm{al}^{17}$ point out the high expectations that community members have for university partners. To avoid breaking trust with the community, academic institutions and professional research organizations should not commit to CBPR unless they are willing to invest a considerable amount of time, energy, and commitment to community members.

Parker et $\mathrm{al}^{18}$ and Davis and Reid ${ }^{19}$ report on the essential need to establish trust in the community and with the community. Doing so may be more difficult in PBRNs, as the research is more spread out and less obvious in any single community. Because PBRNs are geographically distributed, building trust requires engagement in multiple communities and with multiple groups within communities. One first hurdle a PBRN must surmount is building trust with its clinicians (physicians, nurses, and office staff). It is another big step to move out into many communities and attempt to build trust with the community members served by the clinicians. One method for building trust and support of community members might be to include community members in research presentations and publications. Sloane et $\mathrm{al}^{20}$ included 2 members of their community health council on a publication about nutrition and healthy living in Los Angeles.

Several authors outline other essential components of community involvement in research: shared decision making, developing appropriate and responsive research priorities, securing project specific funding, cultural competence, and building and maintaining trust within the community and between the community and the researcher. ${ }^{21,22}$

The lack of adequate resources (money to pay for investigator and community member time and travel) was reported by numerous respondents. Minkler et $\mathrm{al}^{23}$ and McAllister et al, ${ }^{24}$ both call for increased federal and private foundation funding and improved academic support for CBPR. Interestingly, none of our respondents reported lack of academic or institutional support as a barrier to community involvement in their PBRN Many in this area have called for increased university and academic support for community involvement in research. Nyden ${ }^{25}$ describes methods for providing incentives to academic faculty to conduct CBPR. He recommends that university officials provide academic enrichment funds earmarked for participatory research and add participatory research to tenure and promotion guidelines. Similarly, the Commission on CommunityEngaged Scholarship in the Health Professions has called for strengthened academic support for community engagement in research and service. The commis- 
sion recommends promotion and tenure policies that value community engagement. ${ }^{26}$

$\mathrm{NIH}$ and other funding agency study sections may be unfamiliar with community-based participatory research approaches. In true CBPR the research idea and methods emerge from the community and evolve in an iterative process between academic researchers and community partners, a process that often is more highly scrutinized or denigrated by some academic institutions and funders. Funding agencies must be willing to accept-and fund-a stepwise approach to research that includes a first stage of consultation with community members and may involve modification of methods as the research project progresses. It is promising that $\mathrm{AHRQ}$ is interested, as noted in their requirements for PBRNs. The NIH recently released an RFA calling for CBPR projects, and the Centers for Disease Control and Prevention has included CBPR in their special interest project (SIP) RFAs. These funding opportunities will serve to encourage PBRNs to consider community involvement in their research.

Several limitations to this study deserve further discussion. Because there appears to be wide variation in the application of participatory methods in PBRNs, some respondents may not have described all the ways in which they involve community members. Future research may help define a taxonomy for the various levels of community participation that will assist PBRNs in identifying appropriate research methods and the necessary resources for each type of community involvement. We did not receive responses from a number of PBRNs, some of which may be using participatory methods in their network. This study did not identify project-specific outcomes associated with participatory research.

There are striking parallels between PBRN research and CBPR. ${ }^{27}$ Both strive to use ground-up rather than top-down approaches that recognize the limitations of expert knowledge and the strength of common life experience. Both recognize and emphasize the strengths of people and communities (including the community of clinicians) and their capacity for problem solving. As well, both strive to be driven by local priorities rather than only by the priorities of academic researchers. Despite the barriers identified to engage the community, there appears to be an increasing interest in CBPR from investigators, funding agencies, and communities themselves.

Can CBPR be done in practice-based research networks? It appears from our findings and our experience that community members can and will participate in PBRN research. An example of CBPR as part of PBRN research is described in the Supplemental Case Report, which can be found online at http://www.annfammed.
org/cgi/content/full/4/1/8/DC1. (The abstract of this case report can be found in the Appendix at the end of this article.) Without committing enormous amounts of time, community members can affect the research conducted in PBRNs. Community members can help generate research ideas, help ground the research in real patient experiences, assist in refining research methods, help interpret findings, and assist in local dissemination of results. Will participatory research benefit PBRN research? While the literature is replete with successful applications of CBPR in single communities, there are few to no data on the benefits of participatory research in PBRNs. Based on the CBPR literature and the findings of this study, however, we believe that community involvement will enhance PBRN research. Involving the community of patients served by PBRN physicians may be the logical next step to asking important clinical questions that matter to patients, are relevant to physicians, and are rigorously studied in a research setting.

To read or post commentaries in response to this article, see it online at http://www.annfammed.org/cgi/content/full/4/1/8.

Key words: Practice-based research network; community-based participatory research; health services research

Submitted May 11, 2005; submitted, revised, August 8, 2005; accepted August 25, 2005.

Funding support: This study was supported by an Academic Administrative Units Grant (1-D12-HP-0054) from the Health Resources and Services Administration.

\section{References}

1. Minkler M, Wallerstein N. Community-Based Participatory Research For Health. San Francisco, Calif: Jossey-Bass; 2003.

2. Leung MW, Yen IH, Minkler M. Community based participatory research: a promising approach for increasing epidemiology's relevance in the 21st century. Int J Epidemiol. 2004;33:499-506.

3. Green LW, George MA, Frankish CJ, et al. Study of Participatory Research in Health Promotion in Canada. Ottawa, Canada: Royal Society of Canada; 1995.

4. Schneider B, Scissons H, Arney L, et al. Communication between people with schizophrenia and their medical professionals: a participatory research project. Qual Health Res. 2004;14:562-577.

5. Stratford D, Chamblee S, Ellerbrock TV, et al. Integration of a participatory research strategy into a rural health survey. J Gen Intern Med. 2003;18:586-588.

6. Puoane T, Sanders D, Ashworth A, et al. Improving the hospital management of malnourished children by participatory research. Int J Qual Health Care. 2004;16:31-40.

7. Meyer MC, Torres S, Cermeno N, MacLean L, Monzon R. Immigrant women implementing participatory research in health promotion. West J Nurs Res. 2003;25:815-834.

8. Macaulay AC, Commanda LE, Freeman WL, et al. Participatory research maximises community and lay involvement. North American Primary Care Research Group. BMJ. 1999;319:774-778. 
9. North American Primary Care Research Group (NAPCRG). Responsible research with communities: participatory research in primary care. 1998. Available at: http://napcrg.org/responsibleresearch.pdf.

10. Green LA, Lutz LJ. Notions about networks: primary care practices in pursuit of improved primary care. In: AHCPR Conference Proceedings. Primary Care Research: An Agenda for the 90s. Rockville, Md: Department of Health and Human Services; 1990. DHHS Publication Number (PHS) 90-3460.

11. Green LA, Wood M, Becker L, et al. The Ambulatory Sentinel Practice Network: purpose, methods, and policies. J Fam Pract. 1984;18:275280.

12. Small Research Grants for Primary Care Practice-Based Research Networks (PBRNs). Agency for Healthcare Research and Quality (AHRQ); 2003. RFA: HS-03-006.

13. The Centers for Disease Control. Community-based participatory prevention research grants. [Web page]. Available at: http://www.phppo. cdc.gov/od/oser/PRGrants.asp. Accessed: 14 March 2005.

14. National Institutes of Health. Division of Extramural Research and Training [Web Page]. Available at: http://www.niehs.nih.gov/translat/ cbpr/cbpr.htm. Accessed: 14 March 2005.

15. Crabtree BF, Miller WL, eds. Doing Qualitative Research. 2nd ed. Thousand Oaks, Calif: Sage Publications; 1999

16. Frankish CJ, George A, Daniel M, Doyle Waters M, Walker M. Participatory Health Promotion Research in Canada: A Community Guidebook. Ottawa: Health Canada;1997

17. Ammerman A, Corbie-Smith G, St George DM, et al. Research expectations among African American church leaders in the PRAISE! project: a randomized trial guided by community-based participatory research. Am J Public Health. 2003;93:1720-1727.
18. Parker EA, Israel BA, Williams $M$, et al. Community action against asthma: examining the partnership process of a community-based participatory research project. J Gen Intern Med. 2003;18:558-567.

19. Davis SM, Reid R. Practicing participatory research in American Indian communities. Am J Clin Nutr. 1999;69:755S-759S.

20. Sloane DC, Diamant AL, Lewis LB, et al. Improving the nutritional resource environment for healthy living through community-based participatory research. J Gen Intern Med. 2003;18:568-575.

21. Shiu-Thornton S. Addressing cultural competency in research: integrating a community-based participatory research approach. Alcohol Clin Exp Res. 2003;27:1361-1364.

22. Metzler MM, Higgins DL, Beeker CG, et al. Addressing urban health in Detroit, New York City, and Seattle through community-based participatory research partnerships. Am J Public Health. 2003;93:803-811.

23. Minkler M, Blackwell AG, Thompson M, Tamir H. Community-based participatory research: implications for public health funding. Am J Public Health. 2003;93:1210-1213.

24. McAllister CL, Green BL, Terry MA, Herman V, Mulvey L. Parents, practitioners, and researchers: community-based participatory research with early head start. Am J Public Health. 2003;93:1672-1679.

25. Nyden P. Academic incentives for faculty participation in communitybased participatory research. J Gen Intern Med. 2003;18:576-585.

26. Community-Campus Partnerships for Health. Commission on Community-Engaged Scholarship in the Health Professions [Web page]. Available at: http://depts.washington.edu/ccph/kellogg3.html. Accessed: Mar 14, 2005.

27. Minkler M. Using Participatory Action Research to build Healthy Communities. Public Health Rep. 2000;115:191-197.

\section{APPENDIX.}

\section{Abstract: Community Involvement in a Practice-Based Research Network}

Community-based participatory research (CBPR) has become an important method in primary care to improve the relevance of clinical research. The purpose of this article is to describe community involvement in the High Plains Research Network (HPRN), an integrated PBRN in rural Colorado. The HPRN Community Advisory Council (CAC) consists of local community members (farmers, ranchers, school teachers) that has met regularly for 2 years to help guide HPRN research. The necessary ingredients for our CAC included community members committed to improving the health of their community; a meeting space that was centrally

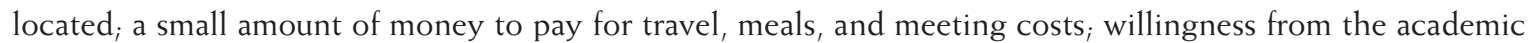
researchers to travel $l_{i}$ and an intentional plan for community member education and research flexibility. Most importantly, our CAC members agreed to participate because they believed the work would benefit their rural community. One unique challenge has been the tension between the community members desire to move quickly on projects and the research staffs' need to follow research protocols. The willingness of the research staff to incorporate CAC ideas, comments, and concerns into grants, manuscripts, and research products and the flexibility of our community members to slow down have led to a close trusting relationship. The CAC has actively participated in research design, qualitative analysis, interpretation of results, and dissemination of findings. Community members can make an important contribution to PBRN research, and the use of a CAC is one method for successfully involving community members in a PBRN.

Westfall JM, VanVorst RF, Main DS, Herbert C. Community-based participatory research in practice-based research networks. Ann Fam Med. 2006;4:8-14. Supplemental case report [The High Plains Research Network Community Advisory Council. Community involvement in a practice-based research network]. Available at: http://www.annfammed.org/cgi/data/4/1/8/DC1/. 